\title{
The assessment of spectral Doppler parameters in uterine arteries of patients with locally advanced squamous cell cervical cancer
}

\author{
Adam Tomalczyk ${ }^{1}$, Bartlomiej Tomasik ${ }^{2}$, Malgorzata Moszynska-Zielinska ${ }^{3}$, \\ Jacek Fijuth ${ }^{3,4}$, Michal Spych ${ }^{4}$, Leszek Gottwald ${ }^{3,4}$ \\ ${ }^{1}$ Department of Radiology - Copernicus Memorial Hospital, Lodz, Poland \\ ${ }^{2}$ Department of Biostatistics and Translational Medicine, Medical University of, Lodz, Poland \\ ${ }^{3}$ Department of Teleradiotherapy, Regional Cancer Centre, Copernicus Memorial Hospital of Lodz, Poland \\ ${ }^{4}$ Department of Radiotherapy, Chair of Oncology, Medical University of Lodz, Poland
}

\begin{abstract}
Objectives: Evaluate spectral Doppler parameters peak systolic velocity (PSV), end diastolic velocity (EDV), resistance index (RI) and pulsatility index (PI) in infiltrated and non-infiltrated uterine arteries of patients with locally advanced (stages II B, III B) squamous cell cervical cancer and their changes during treatment.

Material and methods: the study group included 36 patients aged 35-78 years old. At diagnosis, PSV, EDV, RI and PI in uterine arteries were examined and compared with MRI findings. All patients underwent transvaginal doppler ultrasonography prior to the treatment, after external beam radiation therapy and six weeks after the last application of brachytherapy. Results: The median PSV value in the first examination was higher in infiltrated uterine arteries than compared to non-infiltrated ones $(p=0.001)$. The PSV values for all vessels decreased between the first and the third observation $(p<0.001)$. There was a significant difference in PI values between infiltrated and non-infiltrated uterine arteries between the first and the third examination $(p=0.027)$.

Conclusions: In patients with locally advanced cervical cancer of uterine arteries, assessment of PSV but not EDV, RI or PI can be helpful in differentiating infiltrated from non-infiltrated vessels. In this group of patients, radiotherapy decreases PSV, but not EDV, RI or PI values in uterine arteries. An observation conducted from the onset of radiotherapy to end of the follow-up in uterine arteries reveals that PI, but not RI, PSV or EDV, is different in infiltrated and non-infiltrated vessels. Key words: cervical cancer; locally advanced; spectral Doppler; uterine artery; infiltration
\end{abstract}

Ginekologia Polska 2019; 90, 11: 622-627

\section{INTRODUCTION}

In cervical cancer patients, the mode of treatment depends on staging and parametrial infiltration, which is a critical factor in determining treatment planning. When invasion of the cancer is confirmed in parametrial tissues, locally advanced disease is diagnosed with FIGO stages II B or III B [1, 2].

Clinical pelvic examination has its limitations in evaluation of the parametria. In assessment of parametrial infiltration, MRI is a method of choice with staging accuracy $75-96 \%$, high negative predictive value (94-95\%), specificity of about $94 \%$ and sensitivity of $69 \%$ [3]. CT and PET-CT are used to detect distant metastasis rather than lymph-node involvement, but are poor methods of assessing local tumor extension [3]. Some patients present contraindications to $\mathrm{MRI}$, e.g. claustrophobia, heart pacemakers, neurostimulators and metal implants. Thus, to provide precise assessment of the parametria, other diagnostic methods are being searched [4].

Angiogenesis is a fundamental event in tumor growth, progression and metastasis [5]. The tumor vascular bed differs from the vascular system in healthy tissues. The two typical findings are arteriovenous shunts and new large capillaries or sinusoids devoid of smooth muscle in the walls $[6,7]$. They demonstrate decreased resistance to flow and therefore receive greater flow volume. Thus, a growth of 
carcinomatous tissue is more rapid than the one that would occur in vessels with normal resistance. During radiotherapy, radiation most often damages capillaries, sinusoids and small arteries, whereas lesions of veins are observed less frequently [8]. All these features lead to changes in hemodynamics in both intratumoral vessels and tumor feeding vessels, that can be assessed qualitatively and quantitatively during a Doppler examination [9-14]. Infiltration of uterine arteries is not equal to parametrial involvement since the latter also consists of fatty tissue surrounding both the uterine corpus and the cervix, but it confirms inoperable stage of the cancer.

\section{Objectives}

The aim of this study was to evaluate spectral Doppler parameters, i.e. peak systolic velocity (PSV), end diastolic velocity (EDV), resistance index (RI) and pulsatility index (PI) in infiltrated and non-infiltrated uterine arteries of patients with locally advanced cervical cancer and their changes during treatment.

\section{MATERIAL AND METHODS}

The study group consisted of 36 patients with squamous cell cervical cancer, staged II B and III B, treated at the Department of Teleradiotherapy of the Copernicus Memorial Hospital of Lodz, in 2015-2017. Detailed clinical data of the studied population are presented in Table 1.

The treatment scheme involved application of external beam radiotherapy (EBRT) to the pelvis, uterus, both adnexa and regional lymph nodes up to a dose of $44 \mathrm{~Gy}$, fractionated at $2 \mathrm{~Gy}$, with weekly injections of cisplatin (P) at a dose of $40 \mathrm{mg} / \mathrm{m}^{2}$. In patients with contraindications to $\mathrm{P}$, only EBRT was applied. After EBRT with or without $P$ was completed, high-dose rate brachytherapy (HDR BT) was implemented, fractionated at one application $7 \mathrm{~Gy}$ weekly for four weeks up to a total dose of $28 \mathrm{~Gy}$, or EBRT was continued to the uterus and primary infiltrating tissues, up to a total dose of $60 \mathrm{~Gy}$. Follow-up monitoring was carried out in an oncological outpatient clinic.

All patients underwent an MRI of the pelvis prior to the treatment. The infiltration of uterine arteries was assessed in the MRI, performed with Siemens Magnetom Avanto 1.5 T before the treatment. Evaluation of parametrial vessels invasion was done on T2-weighted turbo spin echo axial plane images.

All patients underwent a transvaginal Doppler ultrasonography (TVDU) prior to the treatment, after EBRT and six weeks after the last application of HDR BT. Both MRI and TVDU were consecutively performed and analyzed by the same examiner with long experience in both methods.

The TVCD examinations were performed using Philips iU22 with $10 \mathrm{MHz}$ endovaginal probe $\mathrm{C} 10-3 \mathrm{v}$. The scanning protocol was the same throughout the study period and all examinations began with the same setting of the ultrasound system. Once parametrial arteries flow signals were identified, velocity waveforms were recorded by placing the sample volume over colored vessels, prior to angle correction. After three uniform consecutive waveforms one of them was manually outlined and spectral Doppler parameters were recorded. The PSV, EDV, RI and PI were analyzed. RI was defined as the ratio of the difference between the PSV and EDV to PS. The PI was defined as the ratio of the difference between the PSV and EDV to the mean velocity. Both RI and PI were calculated automatically and are not dependent on the angle of sampling. Parametrial arteries were assessed bilaterally. Each patient's right and left uterine arteries were analyzed independently.

The group size was estimated using standard power analysis methods. We assumed that clinically-relevant differences would need to exceed $1 / 3$ standard deviation of the analyzed spectral Doppler parameters. Therefore, in order to maintain statistical power $>80 \%$ with a predetermined type 1 error probability $<0.05$ we calculated that a group of 30 patients is the required minimum. This group was

\begin{tabular}{|c|c|c|c|}
\hline \multicolumn{2}{|c|}{ Selected clinical and pathological data } & \multirow{2}{*}{$\begin{array}{l}\mathbf{n} \\
10 \\
16 \\
10\end{array}$} & \multirow{2}{*}{$\begin{array}{l}\text { [\%] } \\
27.8 \\
44.4 \\
27.8\end{array}$} \\
\hline Age [years] & $\begin{array}{l}\leq 50 \\
51-65 \\
>65\end{array}$ & & \\
\hline Pregnancies & $\begin{array}{l}\text { no } \\
\text { yes }\end{array}$ & $\begin{array}{l}3 \\
33\end{array}$ & $\begin{array}{l}8.3 \\
91.7\end{array}$ \\
\hline Deliveries & $\begin{array}{l}0 \\
1-2 \\
\geq 3\end{array}$ & $\begin{array}{l}5 \\
18 \\
13\end{array}$ & $\begin{array}{l}13.9 \\
50.0 \\
36.1\end{array}$ \\
\hline $\begin{array}{l}\text { Menopausal } \\
\text { status }\end{array}$ & $\begin{array}{l}\text { premenopausal } \\
\text { postmenopausal }\end{array}$ & $\begin{array}{l}11 \\
25\end{array}$ & $\begin{array}{l}30.6 \\
69.4\end{array}$ \\
\hline $\begin{array}{l}\text { Other } \\
\text { diseases }\end{array}$ & $\begin{array}{l}\text { arterial hypertension } \\
\text { diabetes } \\
\text { ischemic heart disease }\end{array}$ & $\begin{array}{l}9 \\
1 \\
2\end{array}$ & $\begin{array}{l}25.0 \\
2.8 \\
5.6\end{array}$ \\
\hline $\begin{array}{l}\text { FIGO } \\
\text { staging }\end{array}$ & $\begin{array}{l}\text { II B } \\
\text { III B }\end{array}$ & $\begin{array}{l}29 \\
7\end{array}$ & $\begin{array}{l}80.6 \\
19.4\end{array}$ \\
\hline $\begin{array}{l}\text { WHO } \\
\text { grading }\end{array}$ & $\begin{array}{l}\mathrm{G} 1+\mathrm{G} 2 \\
\mathrm{G} 3\end{array}$ & $\begin{array}{l}30 \\
6\end{array}$ & $\begin{array}{l}83.3 \\
16.7\end{array}$ \\
\hline $\begin{array}{l}\text { Largest } \\
\text { tumor } \\
\text { diameter }\end{array}$ & $\begin{array}{l}<4 \mathrm{~cm} \\
\geq 4 \mathrm{~cm}\end{array}$ & $\begin{array}{l}17 \\
19\end{array}$ & $\begin{array}{l}47.2 \\
52.8\end{array}$ \\
\hline $\begin{array}{l}\text { Tumor } \\
\text { volume }\end{array}$ & $\begin{array}{l}<20 \mathrm{~cm}^{3} \\
20-40 \mathrm{~cm}^{3} \\
>40 \mathrm{~cm}^{3}\end{array}$ & $\begin{array}{l}17 \\
12 \\
7\end{array}$ & $\begin{array}{l}47.2 \\
33.4 \\
19.4\end{array}$ \\
\hline Treatment & $\begin{array}{l}\text { EBRT ( } 60 \mathrm{~Gy} / 2 \mathrm{~Gy}) \\
\text { EBRT ( } 44 \mathrm{~Gy} / 2 \mathrm{~Gy})+\mathrm{HDR} \text { BT } \\
\text { EBRT ( } 44 \mathrm{~Gy} / 2 \mathrm{~Gy})+\mathrm{P}+\mathrm{HDR} \text { BT }\end{array}$ & $\begin{array}{l}1 \\
2 \\
33\end{array}$ & $\begin{array}{l}2.8 \\
5.5 \\
91.7\end{array}$ \\
\hline Total & & 36 & 100.0 \\
\hline
\end{tabular}

EBRT — external beam radiotherapy; HDR BT — high-dose rate brachytherapy; $\mathrm{P}$ - cisplatine 
increased by $20 \%$ to account for missing data, which results in 6 additional patients enrolled.

The statistical analysis was carried out using Statistica 13.1 software (Statsoft, Tulsa, OK, US). Nominal variables were expressed as percentages and analyzed using the Chi-square test with appropriate corrections (the Yates's correction for continuity or the Fisher exact test), if needed. The normality of the distribution of continuous variables was verified with the Shapiro-Wilk test. Continuous variables were presented as medians with $25 \%$ to $75 \%$ values and compared using the Mann-Whitney $U$ test. Paired comparisons across the 3 timepoints were analyzed using the repeated-measures analysis of variance. Sphericity assumption was tested using the Mauchly's test. A multivariable analysis was performed with the application of general linear models. The $p$ values lower than 0.05 were considered statistically significant. The study was approved by the Bioethics Commission of the Medical University of Lodz no.RNN/94/15/KE.

\section{RESULTS}

The univariate analysis revealed that the median PSV value in the first examination was higher in infiltrated uterine arteries than compared to non-infiltrated ones $[30.6 \mathrm{~cm} / \mathrm{s}$ $(18.8-39.9 \mathrm{~cm} / \mathrm{s})$ vs $16.8 \mathrm{~cm} / \mathrm{s}(13.1-22.3 \mathrm{~cm} / \mathrm{s})](p=0.001)$, as shown in Figure 1. This was further confirmed in the multivariate analysis, in which PSV values in infiltrated uterine arteries, detected in an MRI, differed significantly from PSV values of non-infiltrated uterine arteries $(p=0.023)$. In addition, the PSV values for all vessels decreased between the first and the third observation $(p<0.001)$. There was no significant difference in PSV values between infiltrated and non-infiltrated uterine arteries between the first and the third examination ( $p=0.360$; Fig. 2).

Both the univariate and multivariate analyses revealed that there were no differences in median EDV values be-

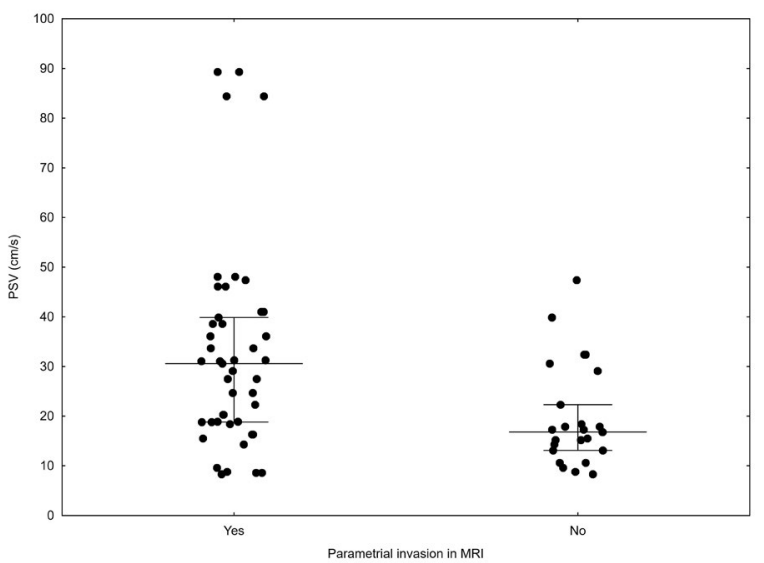

Figure 1. Comparison of PSV values in uterine arteries, depending on parametrial invasion in MRI tween infiltrated and non-infiltrated uterine arteries, measured in the first examination [7.86 (4.97-12.40) vs 9.32 (6.7711.70 ] ( $p=0.523$ and $p=0.459$, respectively), as shown in Figure 3. Between the first and the third examinations, EDV values for all vessels did not significantly change $(p=0.148)$. There was no difference in EDV values between infiltrated and non-infiltrated uterine arteries between the first and the third examination ( $p=0.786$; Fig. 4).

Both the univariate and multivariate analyses revealed that there were no differences in median RI values in the first examination between infiltrated and non-infiltrated uterine arteries $[0.73(0.58-0.78)$ vs $0.66(0.62-0.76)](p=0.568$ and 0.947 , respectively), as shown in Figure 5 . Between the first and the third examinations, RI values for all vessels did not significantly change $(p=0.228)$. There was no difference in RI values between infiltrated and non-infiltrated uterine arteries between the first and the third examination $(p=0.297$; Fig. 6).

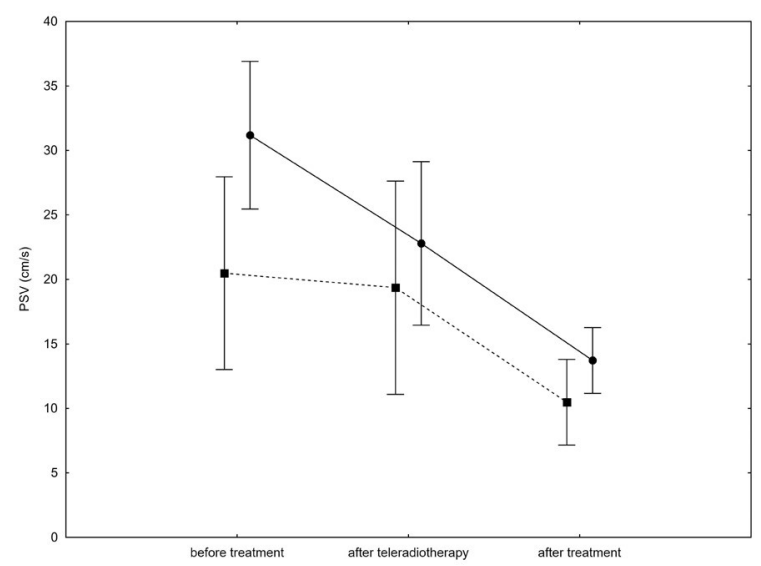

Figure 2. Changes of PSV in uterine arteries during treatment; solid line - parametrial invasion in MRI; broken line - no parametrial invasion in MR

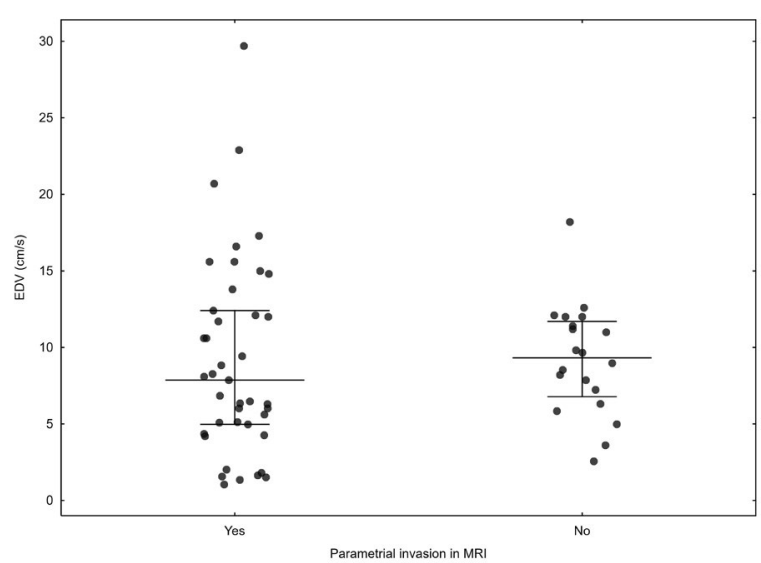

Figure 3. Comparison of EDV values in uterine arteries, depending on parametrial invasion in MRI 


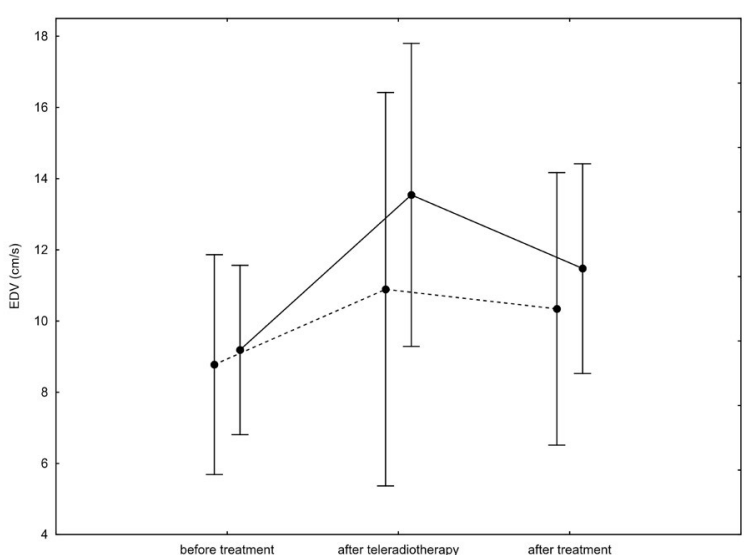

Figure 4. Changes of EDV in uterine arteries during treatment; solid line - parametrial invasion in MRl; broken line - no parametrial invasion in MRI

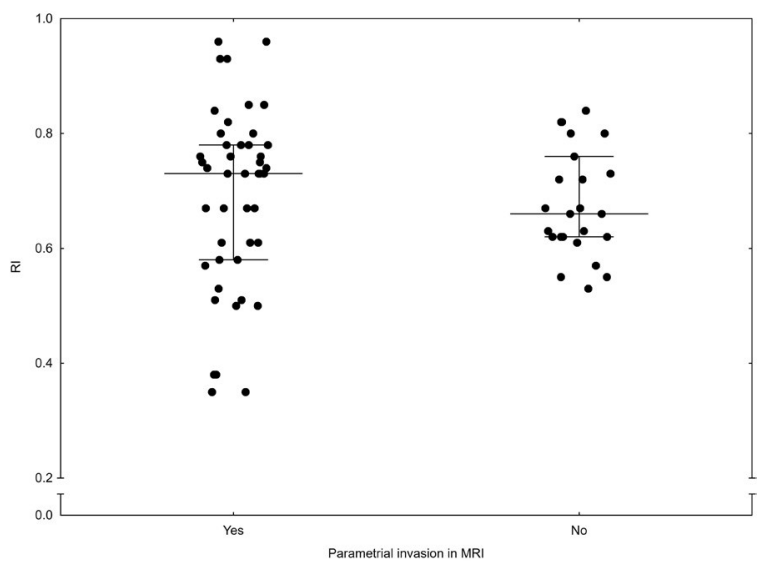

Figure 5. Comparison of RI values in uterine arteries, depending on parametrial invasion in MRI

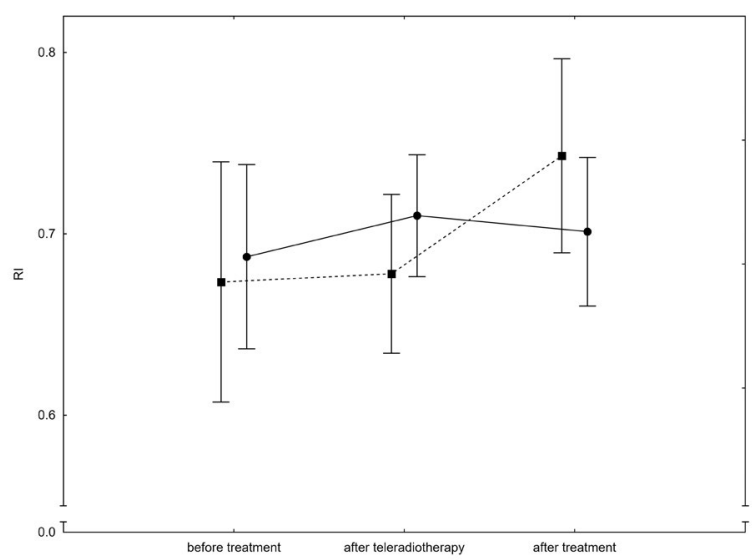

Figure 6. Changes of RI in uterine arteries during treatment; solid line - parametrial invasion in MRI; broken line - no parametrial invasion in MRI

Both the univariate and multivariate analyses revealed that there were no differences in median PI values between

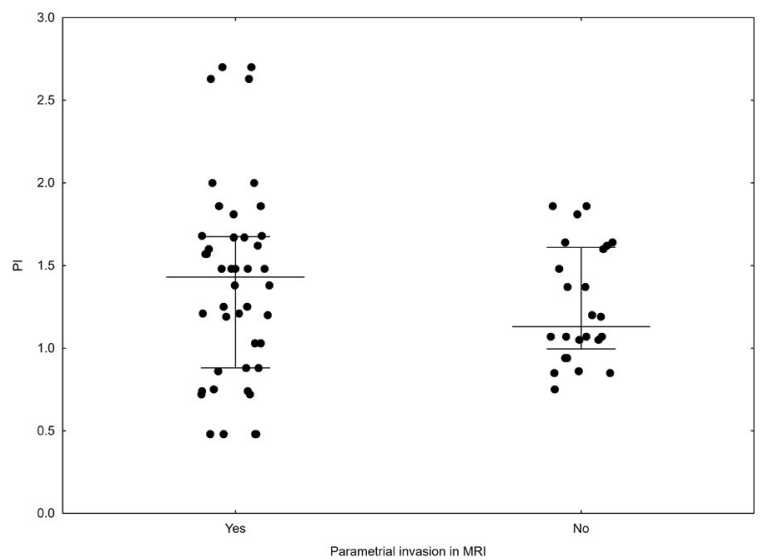

Figure 7. Comparison of Pl values in uterine arteries, depending on parametrial invasion in MRI

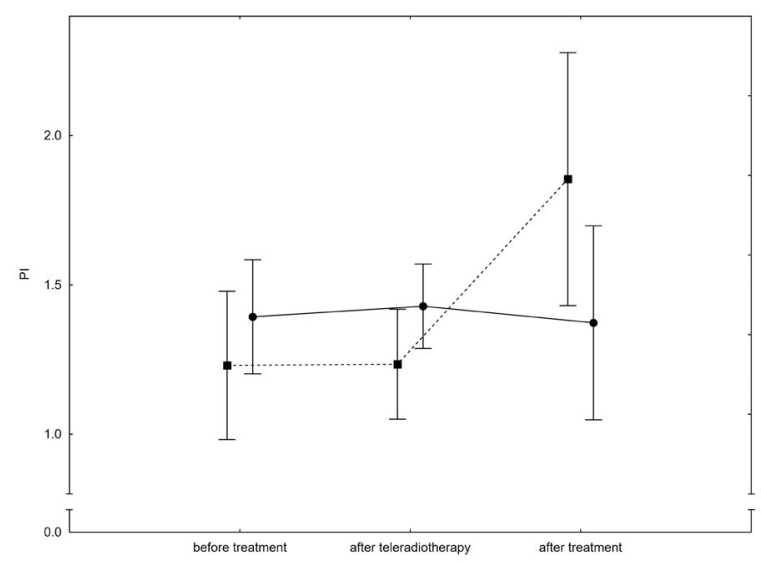

Figure 8. Changes of $\mathrm{PI}$ in uterine arteries during treatment; solid line - parametrial invasion in MRl; broken line - no parametrial invasion in MRI

infiltrated and non-infiltrated uterine arteries, measured in the first examination [1.43 (0.88-1.68) vs $1.13(1.00-1.61)]$ $(p=0.460$ and $p=0.683$, respectively), as shown in Figure 7 . From the first examination to the third one, the difference in $\mathrm{PI}$ values for all vessels was at the limits of statistical significance ( $p=0.058$ ). There was a significant difference in PI values between infiltrated and non-infiltrated uterine arteries between the first and the third examination $(p=0.027$; Fig. 8).

\section{DISCUSSION}

Transvaginal ultrasound (TVUS) and transrectal ultrasound (TRUS) are cost-efficient diagnostic tools, characterized with high specificity and moderate sensitivity in evaluating parametrial involvement in cervical cancer patients [15-19]. Fischerova et al. claimed that ultrasounds are superior to MRIs, as it enables to accurately predict parametrial infiltration in cervical cancer patients. Sensitivity 
values, obtained with the application of these two imaging techniques, are $83 \%$ and $50 \%$, respectively, whereas specificity values are $100 \%$ and $98 \%$, respectively [15]. Results obtained by Testa et al. [16] (sensitivity $60 \%$ vs $40 \%$ and specificity $89 \%$ vs $89 \%$ ) and by Epstein et al. [17] (sensitivity $77 \%$ vs $69 \%$ and specificity $98 \%$ vs $92 \%$ ) were similar. Moloney et al. [20] found higher sensitivity rates ( $86 \%$ vs $40 \%$ ) but lower specificity values ( $20 \%$ vs $78.8 \%$ ) for TVUS in comparison with values obtained with the use of MRIs with regards to detection of parametrial infiltration. Chiappa et al. [21] described similar with MRI diagnosis of parametrial infiltration for 2D and 3D ultrasound in $76 \%$ and $79 \%$, respectively. The usefulness of TVUS as a diagnostic but also as a prognostic tool can be improved when it is accompanied by assessment of parametrial and intertumoral blood vessels in color and power Doppler examination [13, 22, 23].

Since the early 1990s, there have been efforts to make TVDU a valuable method, that can enable identification of infiltrated parametrial vessels. Initial studies, assessing blood flow hemodynamics in cervical cancer, focused on uterine arteries and cervical branches of uterine arteries, but those reports compared cervical cancer patients with healthy volunteers [24, 25]. Enzelsberger et al. [24] found that cervical cancer patients demonstrated significantly lower median PI values, both in uterine and cervical arteries. Similar findings, which also regarded RI values, were presented by Breyer et al. [25]. Additionally, Bolla et al. [26] found a positive correlation between tumor diameter, uterine artery end-diastolic velocity and PSV, but not RI or PI. In our study, only patients with locally advanced cervical cancer were evaluated. Spectral Doppler parameters of infiltrated and not infiltrated uterine arteries before, during and after the treatment were analyzed. We did not observe any difference in EDV, $\mathrm{PI}$ or RI values between infiltrated and non-infiltrated vessels before the treatment, but PSV value was significantly higher in infiltrated uterine arteries. Our results correspond to those obtained by Bolla et al. [26] and cited above. In our opinion, especially when MRI cannot be used for diagnostic purposes, a high PSV value in uterine arteries can be valuable information.

Changes in spectral Doppler parameters in uterine arteries, observed during treatment of locally advanced cervical cancer, were a topic of our interest as well. We observed decreased PSV values between the first and the last examination, similarly in infiltrated and non-infiltrated vessels. When analyzing EDV, RI and PI values, some changes between infiltrated and non-infiltrated uterine arteries were observed, particularly between the second and the third examination.

Our results can be considered preliminary data only and must be confirmed in more extensive materials. The main strength of our study is its prospective design. This study describes first prospective correlation between spectral
Doppler parameters in parametrial arteries and MRI images. In our paper analysis of both TVCD and MRI images by the same examiner raises the accuracy of interpretation, but we are aware that it can also be a limitation with possibility of a bias. Another limitation of our study is reproducibility of PSV and EDV measurements which are dependent on the angle of sampling and may alter due to different operators.

\section{CONCLUSIONS}

1. In patients with locally advanced cervical cancer of uterine arteries, assessment of PSV but not EDV, RI, or PI can be helpful in differentiation of infiltrated and non-infiltrated vessels.

2. In this group of patients, radiotherapy decreases PSV values in uterine arteries. Such a decrease is not observed for EDV, RI and PI values.

3. An observation conducted from the onset of radiotherapy to end of the follow-up in uterine arteries reveals that $\mathrm{PI}$, but not EDV, RI or PSV, is different in infiltrated and non-infiltrated vessels.

\section{REFERENCES}

1. Bhatla N, Aoki D, Sharma DN, et al. Cancer of the cervix uteri. Int J Gynaecol Obstet. 2018; 143 Suppl 2: 22-36, doi: 10.1002/ijgo.12611, indexed in Pubmed: 30306584.

2. Kato T, Watari H, Takeda M, et al. Multivariate prognostic analysis of adenocarcinoma of the uterine cervix treated with radical hysterectomy and systematic lymphadenectomy. J Gynecol Oncol. 2013; 24(3): 222-228, doi: 10.3802/jgo.2013.24.3.222, indexed in Pubmed: 23875071.

3. Testa A, Legge ADi, Blasis IDe, et al. Imaging techniques for the evaluation of cervical cancer. Best Pract Res Clin Obstet Gynaecol. 2014; 28(5): 741-768, doi: 10.1016/j.bpobgyn.2014.04.009.

4. Sammet S. Magnetic resonance safety. Abdom Radiol (NY). 2016; 41(3): 444-451, doi: 10.1007/s00261-016-0680-4, indexed in Pubmed: 26940331.

5. Folkman J, Watson K, Ingber D, et al. Induction of angiogenesis during the transition from hyperplasia to neoplasia. Nature. 1989; 339(6219): 58-61, doi: 10.1038/339058a0, indexed in Pubmed: 2469964.

6. Gammill SL, Shipkey FH, Himmelfarb EH, et al. Roentgenology-pathology correlative study of neovascularity. AJR Am J Roentgenol. 1976; 126(2): 376-385, doi: 10.2214/ajr.126.2.376, indexed in Pubmed: 175707.

7. Taylor KJ, Ramos I, Carter D, et al. Correlation of Doppler US tumor signals with neovascular morphologic features. Radiology. 1988; 166(1 Pt 1): 57-62, doi: 10.1148/radiology.166.1.2447604, indexed in Pubmed: 2447604.

8. Fajardo LF, Berthrong M. Vascular lesions following radiation. Pathol Annu. 1988; 23 Pt 1: 297-330, indexed in Pubmed: 3387138.

9. Alcázar JL, Castillo G, Martínez-Monge R, et al.Transvaginal color Doppler sonography for predicting response to concurrent chemoradiotherapy for locally advanced cervical carcinoma. J Clin Ultrasound. 2004; 32(6): 267-272, doi: 10.1002/jcu.20033, indexed in Pubmed: 15211671.

10. Alcázar JL, Jurado M. Transvaginal color Doppler for predicting pathological response to preoperative chemoradiation in locally advanced cervical carcinoma: a preliminary study. Ultrasound Med Biol. 1999; 25(7): 1041-1045, doi: 10.1016/s0301-5629(99)00063-0, indexed in Pubmed: 10574335.

11. Kerimoğlu U, Akata D, Hazirolan $T$, et al. Evaluation of radiotherapy response of cervical carcinoma with gray scale and color Doppler ultrasonography: resistive index correlation with magnetic resonance findings. Diagn Interv Radiol. 2006; 12(3): 155-160, indexed in Pubmed: 16972223.

12. Testa AC, Ferrandina G, Distefano M, et al. Color Doppler velocimetry and three-dimensional color power angiography of cervical carcinoma. Ultrasound Obstet Gynecol. 2004; 24(4): 445-452, doi: 10.1002/uog.1703, indexed in Pubmed: 15343602. 
13. Wu YC, Yuan CC, Hung JH, et al. Power Doppler angiographic appearance and blood flow velocity waveforms in invasive cervical carcinoma. Gynecol Oncol. 2000; 79(2): 181-186, doi: 10.1006/gyno.2000.5889, indexed in Pubmed: 11063641.

14. Pirhonen JP, Grenman SA, Bredbacka AB, et al. Effects of external radiotherapy on uterine blood flow in patients with advanced cervical carcinoma assessed by color Doppler ultrasonography. Cancer. 1995; 76(1): 67-71, doi: 10.1002/1097-0142(19950701)76:1<67::aid-cncr28 20760109>3.0.co;2-0, indexed in Pubmed: 8630878.

15. Fischerova D, Cibula D, Stenhova $H$, et al. Transrectal ultrasound and magnetic resonance imaging in staging of early cervical cancer. Int J Gynecol Cancer. 2008; 18(4): 766-772, doi: 10.1111/j.1525-1438.2007 .01072.x, indexed in Pubmed: 17892456.

16. Testa AC, Ludovisi M, Manfredi R, et al. Transvaginal ultrasonography and magnetic resonance imaging for assessment of presence, size and extent of invasive cervical cancer. Ultrasound Obstet Gynecol. 2009; 34(3): 335-344, doi: 10.1002/uog.7325, indexed in Pubmed: 19705403.

17. Epstein E, Testa A, Gaurilcikas A, et al. Early-stage cervical cancer: tumor delineation by magnetic resonance imaging and ultrasound - a European multicenter trial. Gynecol Oncol. 2013; 128(3): 449-453, doi: 10.1016/j.ygyno.2012.09.025, indexed in Pubmed: 23022593.

18. Gaurilcikas A, Vaitkiene D, Cizauskas A, et al. Early-stage cervical cancer: agreement between ultrasound and histopathological findings with regard to tumor size and extent of local disease. Ultrasound Obstet Gynecol. 2011; 38(6): 707-715, doi: 10.1002/uog.9037, indexed in Pubmed: 21538643.

19. Csutak C, Badea R, Bolboaca SD, et al. Multimodal endocavitary ultrasound versus MRI and clinical findings in pre- and post-treatment advanced cervical cancer. Preliminary report. Med Ultrason. 2016;
18(1): 75-81, doi: 10.11152/mu.2013.2066.181.csk, indexed in Pubmed: 26962558.

20. Moloney F, Ryan D, Twomey M, et al. Comparison of MRI and high-resolution transvaginal sonography for the local staging of cervical cancer. J Clin Ultrasound. 2016; 44(2): 78-84, doi: 10.1002/jcu.22288, indexed in Pubmed: 26294324.

21. Chiappa V, Di Legge A, Valentini AL, et al. Agreement of two-dimensional and three-dimensional transvaginal ultrasound with magnetic resonance imaging in assessment of parametrial infiltration in cervical cancer. Ultrasound Obstet Gynecol. 2015; 45(4): 459-469, doi: 10.1002/uog.14637, indexed in Pubmed: 25091827.

22. Alcázar JL, Castillo $G$, Jurado $M$, et al. Intratumoral blood flow in cervical cancer as assessed by transvaginal color doppler ultrasonography: Correlation with tumor characteristics. Int J Gynecol Cancer. 2003; 13(4): 510-514, doi: 10.1046/j.1525-1438.2003.13302.x, indexed in Pubmed: 12911729.

23. Hsu KF, Su JM, Huang SC, et al. Three-dimensional power Doppler imaging of early-stage cervical cancer. Ultrasound Obstet Gynecol. 2004; 24(6): 664-671, doi: 10.1002/uog.1756, indexed in Pubmed: 15517537.

24. Enzelsberger H, Skodler WD, Vavra N, et al. Ultrasonic Doppler flow studies of the uterine arteries in women with cervix cancer. Gynecol Obstet Invest. 1991; 32(2): 112-114, doi: 10.1159/000293007, indexed in Pubmed: 1748318.

25. Breyer B, Despot A, Predanic $M$, et al. Characteristics of blood flow in cancer of the uterine cervix. Ultrasound Obstet Gynecol. 1993; 3(4): 268-270, doi: 10.1046/j.1469-0705.1993.03040268.x, indexed in Pubmed: 12797274.

26. Bolla D, In-Albon S, Papadia A, et al. Doppler Ultrasound Flow Evaluation of the Uterine Arteries Significantly Correlates with Tumor Size in Cervical Cancer Patients. Ann Surg Oncol. 2015; 22 Suppl 3: S959-S963, doi: 10.1245/s10434-015-4655-4, indexed in Pubmed: 26036189. 